\title{
Unauthorized Access to Computer System
}

National Cancer Institute

\section{Source}

National Cancer Institute. Unauthorized Access to Computer System. NCI Thesaurus.

Code C63259.

Problem associated with an access that was not permitted to the computer system that may lead to modification of program, corruption of data, or and break in network security. This concept is closely associated with computer integrity which is the degree to which a system or component prevents unauthorized access to, or modification of, computer programs or data. 